\title{
The Effect of Work Environment on Job Satisfaction: Evidence from the Banking Sector in Ghana
}

\author{
George Kafui Agbozo ${ }^{1}$, Isaac Sakyi Owusu ${ }^{2}$, Mabel A. Hoedoafia ${ }^{1}$, , Yaw Boateng Atakorah ${ }^{3}$ \\ ${ }^{1}$ Faculty of Economics and Business Administration, Catholic University College of Ghana, Fiapre, Sunyani, Ghana \\ ${ }^{2}$ Institute of Distance Learning, Kwame Nkrumah University of Science and Technology, Kumasi, Ghana \\ ${ }^{3}$ Department of Economics, Kwame Nkrumah University of Science and Technology, Kumasi, Ghana
}

Email address:

georgeagbozo@hotmail.com (G. K. Agbozo), mhoedoafia@yahoo.com (M. A. Hoedoafia), atakorahboateng@gmail.com (Y. B. Atakorah) ${ }^{*}$ Corresponding author

\section{To cite this article:}

George Kafui Agbozo, Isaac Sakyi Owusu, Mabel A. Hoedoafia, Yaw Boateng Atakorah. The Effect of Work Environment on Job Satisfaction: Evidence from the Banking Sector in Ghana. Journal of Human Resource Management. Vol. 5, No. 1, 2017, pp. $12-18$. doi: $10.11648 /$ j.jhrm.20170501.12

Received: December 27, 2016; Accepted: January 12, 2017; Published: February 10, 2017

\begin{abstract}
This paper examined the effect of work environment on job satisfaction with the spotlight on a merchant bank in Ghana. Among other objectives, the paper set out to ascertain the impact of physical and mental environment on employees' performance, to know the overall satisfaction level of employees in the bank and study whether physical, social and psychological work environment affect job satisfaction. Stratified sampling technique was adopted to select the sample for the study. Questionnaire was used as the research instrument while Statistical Package for Social Science (SPSS) was employed to analyze the data gathered from the field study. Findings of the study indicated that most of the staff at the bank are satisfied with their work environment especially the physical ambiance. The paper concludes that the environment has a significant effect on employees' satisfaction. The findings of the paper emphasize the need for management to improve the work environment of employees to boost productivity.
\end{abstract}

Keywords: Social Interactions, Employee Efficiency, Working Behaviours, Management Practices, Worker Motivation

\section{Introduction}

The importance of work environment in job satisfaction cannot be underestimated. Why do some feel good with their job schedules and accomplish better than others? Whiles some gladly look forward to the next day's activities at work, others feel clouded with the mere thought of the work ahead and the next day's activities. Several studies have been conducted to look into the relationship between employees' level of work satisfaction and longevity [1] to employee performance [2]. In fact, all these studies had one thing in common, thus, employee satisfaction correlates with employees' work environment. Excessive performance over the years has been of prime concern to industrialists, responsible employees, social workers, industrial and organizational psychologists, among others.

The conception of workers' satisfactions with their jobs was originally developed from the study by Elton Mayo in the late 1920s and early 1930s at Chicago, a Western Electric Company plant called Hawthorne. The result of the study brought to light that the working behaviors of workers can be impacted upon by their sentiments. Social interactions along with psychological elements are the core bases of contentment with one's job or satisfaction with work and efficiency in personnel [3].

Job satisfaction has become the pillar on which performance of employees is hinged. The most important goal among others of an organization is to exhaust the possibilities of getting the best employee performance in order to accomplish set objectives [4].

The working environment is one of the most crucial factors which influence the level of satisfaction as well as motivation of its employees. According to [5] social, organizational and physical factors are impetus for task and activity which consequently impact the performance of workers'. The productivity of employees is determined 
excessively by the environment in which they work. The utmost significant empirical evidence which indicates the deteriorating working conditions of an organization has to do with the truncated job satisfaction rate [6].

Most managers link workers movement from one job to the other with better conditions of services. However, [7] is of the view that workers leave because of poor management practices or toxic cultures. This cavernous disparity between belief and reality keeps organizations from addressing the costly problems of employee extrication and regrettable turnover with on-target solutions. A deeper understanding of why people leave are not captured in exit interviewing to assist organizations in identifying, preventing, and correcting the root causes of these problems. To establish and confirm how to satisfy employees via manipulation of the environment then becomes of great interest to management of various organizations. To this effect, the paper sought to examine the effect of work environment on job satisfaction in Ghana. Specifically, this paper set out to answer the following questions; (a) does the physical, social and psychological work environment affect job satisfaction? (b) how does the physical and mental environment impact employees? (c) what is the overall satisfaction level of employees at the bank?

The next section reviews relevant literature on the nexus between work environment and employee job satisfaction. Section three describes the methods employed whilst the findings are presented and discussed in section four. The last section concludes.

\section{Literature Review}

\subsection{Work Environment}

An attractive and supportive work environment is critical to job satisfaction. Work environment have numerous properties that may influence both physical and mental wellbeing. A quality work spot is fundamental to keep workers on their various task and work effectively. A good workplace is checked by such characteristics as competitive wages, trusting relationship between the employees and management, equity and fairness for everyone, and a sensible work load with challenging yet achievable goals. A composite of all these conditions makes the work station the best possible working conditions for employees to work with high level of satisfaction. As a profit oriented organization, creating an enabling environment for satisfied employees is a lead to requisite bottom lines.

Work environment can be grouped into three distinct but intertwined forms. These are Physical work environment, psychological work environment and social work environment.

According to [8], supportive work environments help workers to perform normal duties more effectively, making best use of their knowledge, skills and competences and the available resources in order to provide high-quality services.

\subsubsection{Physical Work Environment}

This is the working environment that deals with the physical or tangibles at the setting where job is performed. It includes things like machinery, office layout, temperature, ventilation and lighting. It also includes noise level and space. Aspects of work such as heat, noise, and lighting have been shown to affect a number of psychological processes in both direct and indirect ways. Noise, for example, may impair the cognitive performance of certain kinds of tasks [9].

The physical work environment setting can impact on the level and nature of social interaction between co-workers. The design of open plan offices, for example, and other aspects of the physical lay-out may determine the kinds of interactions that can take place [10]. The physical environment may offer more or less physical safety. A study by [11] found that whenever there is an improvement in the physical design of office building, productivity through employee performances is increased by about 5-10 percent. Similarly, [12] concluded that the type and quality of lighting system at the workplace promotes working experience of employees which then results to increased productivity. Again, [13] findings revealed that lighting, noise, colour and air quality impact employee productivity. Concerns about accidents or injury are also likely to have some effect on psychological well-being.

\subsubsection{Psychological Work Environment}

The psychological work environment can be considered particularly as those elements of the workplace which are pertinent to worker conduct. By behaviour, the three related types of psychological phenomena are considered: affect (e.g. emotions, mood, psychological symptoms, affective disorders); cognitions (e.g. attitudes, perception, decisionmaking); and behaviours (e.g. effectiveness, absence, motivation). The psychological work environment is therefore the set of those characteristics of work environment that affect how the worker feels.

The psychological work environment provides a good description of the mental activities that a worker undertakes during working hours or at post. Psychological work environment include good descriptions and references to other sources of information on stress, bullying, working requirements, cooperation and conflict, etc. Stress and wellbeing are themes within the psychological work environment. Workers think about the following but not limited to, the nature of work, wages that will be earned, opportunity for growth and the like. These factors affect the level of contentment of an employee and in effect impacts on his or her performance. A study by [14] found that, when there is a significant change in compensation, promotions and benefits, workers become satisfied and increases productivity.

\subsubsection{Social Work Environment}

The social work environment deals with relationships at job settings. It includes communication styles, relationship between superiors and subordinates. It also includes relationship among coworkers, the readiness of others to assist and team work. To achieve a progressive work environment, personal respect for personnel at every levels of an establishment is vital in operations. Personal respect in the workplace includes but not limited to such issues as 
discrimination and segregation based on age, gender or racial background, sexual harassment and the role of personal politics in forming workplace relationships. According to [15] there is the need for managers to play the role of facilitators to help address work barriers to improve productivity.

\subsection{Job Satisfaction}

Grounded on evaluation among analysis of literature in job satisfaction, many researchers have defined job satisfaction differently. Job Satisfaction according to [16], is "an affective and emotional response to various facets of one's job". [17] describes it as "being an emotional response that results from the employee's perceived fulfillment of their needs and what they believe the company to have offered". Even though in recent times researchers have tried to replicate current theoretical footings of job satisfaction, [18] definition which happens to be one of the initial definitions of this model is still the most cited. He defined job satisfaction as "any combination of psychological, physiological, and environmental circumstances that causes a person truthfully to say, I am satisfied with my job" [18].

In general, most definitions cover the emotional feeling an employee has concerning their job. This could be the job in general or their attitudes towards specific features of it, such as: their colleagues, salary or working conditions [19]. In addition, the extent to which work outcomes meet or exceed expectations may determine the level of job satisfaction.

Therefore, it appears that the most important situational effect on job satisfaction is what the job itself is linked to and may be the most important personality trait to predict job satisfaction core self-assessment. It is evident that some other personality mannerisms, such as extraversion and scrupulousness, can also affect job satisfaction [20].

\section{Research Methodology}

\subsection{Research Design}

The paper adopted a case study approach of descriptive research method due to its flexibility in terms of the approach it gives, by means of an in-depth and holistic investigation. It has the aim of collecting a rich level descriptions from those participating in the study by permitting them to describe what they experience and feel in their own terms [21].

\subsection{Population}

The population of the study was the employees of a bank in Ghana with a focus on two zones that stretches geographically from as far as New Abirem in the Eastern region of Ghana to Tamale in the northern region. The reason for the selection of these zones and their branches was that these northern zones are highly representative with respect to branch sizes ranging from big through medium to small branch sizes.

\subsection{Sample Size and Sampling Procedure}

A sample size of 105 out of 209 staff was selected for the study. A stratified sampling technique was used first and then followed by a systematic random sampling technique. Branches were grouped into bigger branches, medium branches and smaller branches. Branches in the three strata were numbered and every odd number selected. A census approach was then used on all the staff of the selected branches.

\subsection{Research Instrument}

Questionnaire was used as the data collection instrument. It comprised of both open-ended and close-ended questions.

\subsection{Organizational Profile}

The bank ((name withheld for ethical reasons and confidentiality) is registered as a private limited liability company under the company's code to do banking business. It was given a universal banking license following Bank of Ghana's introduction of Universal Banking in 2003.

The bank is present in other countries and has representative offices across Africa. It has grown consistently in Ghana over the years and has become one of the prominent banks in the country. It is a well-known brand in the banking industry and listed on the Ghana Stock Exchange (GSE). The bank has strategically shifted from a principally wholesale to a retail bank.

\section{Results}

\subsection{Socio-demographic Characteristics of Employees}

In table one below, a summary of the socio-demographic characteristics of respondents are presented.

Table 1. Socio-demographic characteristics of employees.

\begin{tabular}{lll}
\hline Characteristics & Total Responses & Percentage \\
\hline Sex & & \\
Male & 63 & 60 \\
Female & 42 & 40 \\
Age & & \\
$18-25$ & 4 & 3.8 \\
$26-30$ & 27 & 25.7 \\
$31-35$ & 37 & 35.2 \\
$36-40$ & 20 & 19 \\
$41-45$ & 12 & 11.4 \\
Above 45 & 5 & 4.7 \\
Education & & \\
Diploma/HND & 23 & 21.9 \\
$1^{\text {st }}$ Degree & 51 & 48.6 \\
$2^{\text {nd }}$ Degree & 19 & 18.1 \\
Others & 12 & 11.4 \\
Rank & & \\
Management & & \\
Staff & 11 & 10 \\
Senior Staff & 45 & 43 \\
Junior Staff & 49 & 47 \\
Experience (years) & & \\
1-5 & 37 & 35 \\
6-10 & 41 & 39 \\
$11-15$ & 21 & 20 \\
Above 16 & 6 & 6 \\
\hline
\end{tabular}

Source: Field Data, 2015 
Out of the total respondents of 105, majority $60 \%$ (63) were males while $40 \%$ (42) were females.

On the age distribution, majority $35.2 \%$ (37) were between the ages of 31-35. Only few respondents were between 18-25 years and above 45 years with $3.8 \%(4)$ and $4.9 \%(5)$ respectively.

Additionally, table 1 indicates that most workers $48.6 \%(51)$ had completed first degree. $21.9 \%$ and $18.1 \%$ had earned Diploma/HND and second degree respectively, while $11.4 \%$ had earned other professional qualifications including charted markers, accountant and management. Furthermore, on the job rank, majority, $47 \%$ of the respondents were junior staff followed by $43 \%$ if senior staff and the least, $10 \%$ been branch management staff. On years of experience, 35\% had spent between 1-5 years with the bank. 39\% had spent between 6-5 years working with the bank. $21 \%$ and $6 \%$ had spent $11-15$ years and above 16 years with the bank respectively.

\subsection{Degree at Which Physical, Social and Psychological Factors Affect Job Satisfaction}

In accessing the degree at which staff are affected by the various factors at work, $62 \%$ of respondents ranked physical environment as crucial to their satisfaction which must be maintained or improved upon. These respondents are concerned about ambiance, level lamination, temperature of working area and office layout. $23(22 \%)$ out of the 105 respondents were much concerned about social relationships at work. They fancy communal living and work. 17\% are more interested in job content. These ones take into consideration the level of monotony in a job, job complexity, recognition from job and others. See figure 1 below for the details of the responses.

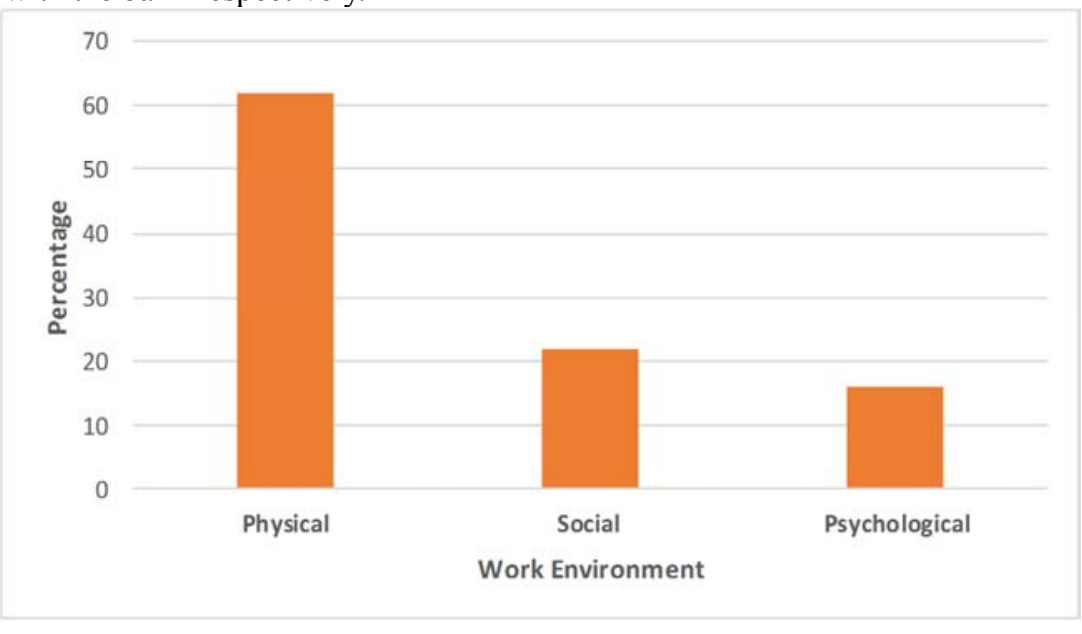

Source: Field Data, 2015

Figure 1. Degree at which factors affect job environment of employees.

The results corroborate that of [22] whose study of employees in Sugar factories in India revealed that about $70.35 \%$ of them agreed that their performance is affected by both their physical and mental work environment.

Generally, majority of the respondents endorsed improvement in physical work environment to other equally important factors. This result corresponds to that of [12] and [13] where it was found in their studies that lighting and air quality have influence on the satisfaction level and performance of employees.

\subsection{Physical Work Environment and Employee Satisfaction}

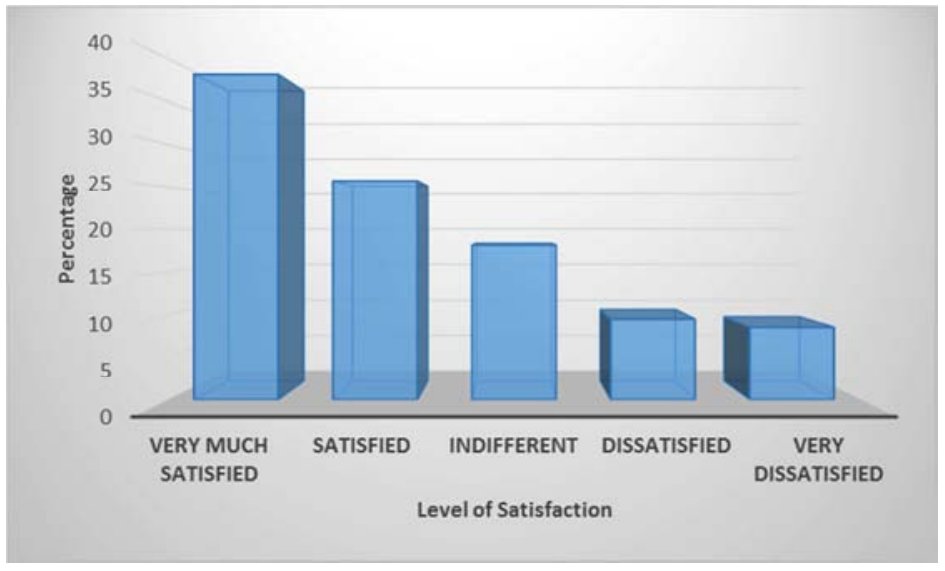

Source: Field Data, 2015

Figure 2. Physical Work Environment and Employee Satisfaction. 
Out of the 105 respondents, $40(38 \%)$ were very much satisfied with the overall physical environment of their working area. $27(26 \%)$ were satisfied with their physical environment. $19(18 \%)$ were indifferent about the physical environment of their working area whiles $10 \%$ and $8 \%$ were dissatisfied and very dissatisfied respectively of their physical environment at work. These responses included the adequacy of the lighting system, temperature suitability noise level and office layout. The responses have been summarized in figure 2 above.

\subsection{Mental Environment and Employee Satisfaction}

\subsubsection{Level of Employees' Anxiety in Relation to Being Redundant}

Out of the total of 105 respondents, 2 employees (2\%) to a very large extent felt anxious of being laid off and $9 \%$ were worried of the security of their jobs. $11 \%$ of the respondents were to a certain degree anxious of the security of their jobs, $55 \%$ and $23 \%$ to a small extent and to a very small extent respectively felt insecured. These ones hardly thought of becoming redundant. Considering the number of respondents who felt secured with their jobs, a lot of staff will work without any taint of fear. This is in line with the findings of [23] that job security is a key contributor to employee job satisfaction.

\subsubsection{How Staff Get Help and Support from Colleagues and Immediate Supervisor}

$39(37 \%)$ of the respondents posited that they always get assistance from colleagues and immediate supervisor. 19 (18\%) respondents stated they often get assistance from their colleagues and immediate. 15 (14\%) staff responded that they sometimes get assistance when the need arises. 30 and 2 respondents stated they seldomly and hardly ever or never gets assistance when the need arises from colleagues and immediate supervisors.

This shows that even though closed to $55 \%$ are having a very conducive social environment to work within, quite a number are not getting the needed support at their work places. Table 2 below depicts a summary of respondents' views.

Table 2. Staff support from colleagues and immediate supervisor.

\begin{tabular}{lll}
\hline Condition of service & Total Responses & Percentage \\
\hline Always & 39 & $37 \%$ \\
Often & 19 & $18 \%$ \\
Sometimes & 15 & $14 \%$ \\
Seldom & 30 & $29 \%$ \\
Never/hardly ever & 2 & $2 \%$ \\
Totals & 105 & $100 \%$ \\
\hline
\end{tabular}

Source: Field work, 2015

\subsubsection{How Cordial Communication Is Among Colleagues and Immediate Supervisor}

According to the responses received, 46 (44\%) out of the 105 respondents felt they had a cordial communication to a very large extent among themselves. $25(24 \%)$ to a large extent had a cordial communication with their colleagues immediate supervisor. $11(10 \%)$ felt there was to some extent a cordial communication with colleagues and immediate supervisor. However, $17 \%$ and $5 \%$ to a small extent and to a very small extent respectively believed. Majority of the respondents felt there was a cordial communication among staff of the bank. Find below in table 3, a summary of the responses.

Table 3. Cordial communication among colleagues and immediate supervisor.

\begin{tabular}{lll}
\hline Degree of cordial communication & Total Responses & Percentage \\
\hline To a very large extent & 47 & $45 \%$ \\
To a large extent & 25 & $24 \%$ \\
Somewhat & 10 & $10 \%$ \\
To a small extent & 18 & $17 \%$ \\
To a very small extent & 5 & $5 \%$ \\
Totals & 105 & $100 \%$ \\
\hline
\end{tabular}

Source: Field work, 2015

\subsection{Social Work Environment and Employee Job Satisfaction}

\subsubsection{How Staff Get Help and Support from Colleagues and Immediate Supervisor}

$39(37 \%)$ out of the 105 understudied responded they always get assistance from colleagues and immediate supervisor. $19(18 \%)$ respondents stated they often get assistance from their colleagues and immediate. $15(14 \%)$ staff responded that they sometimes get assistance when the need arises. 30 and 2 respondents stated they seldomly and hardly ever or never gets assistance when the need arises from colleagues and immediate supervisors.

This shows that even though closed to $55 \%$ are having a very conducive social environment to work within, quite a number are not getting the needed support at their work places.

\subsubsection{Communication Among Colleagues and Immediate Supervisor}

According to the responses received, 46 (44\%) out of the 105 understudied felt they had a cordial communication to a very large extent among themselves. $25(24 \%)$ to a large extent had a cordial communication with their colleagues immediate supervisor. $11(10 \%)$ felt there was to some extent a cordial communication with colleagues and immediate supervisor. However, $17 \%$ and $5 \%$ to a small extent and to a very small extent respectively believed. Majority of the respondents felt there was a cordial communication among staff of the bank. Below in table 2, the responses have been summarized.

\subsection{The Overall Satisfaction Level of Employees in Their Work Environment}

In accessing the overall level of satisfaction of employees at the bank, staff were asked how they felt about the working conditions of the bank. In response, $15(14 \%)$ out of the 105 
respondents felt satisfied to a very large extent. 41 (39\%) responded satisfied to a large extent. $5 \%$ of respondent were indifferent with their level of satisfaction. However, $29 \%$ and $13 \%$ of respondents were to a small extent and to a very small extent respectively satisfied of the working conditions of the bank. These details have been summarized in figure 3 below.

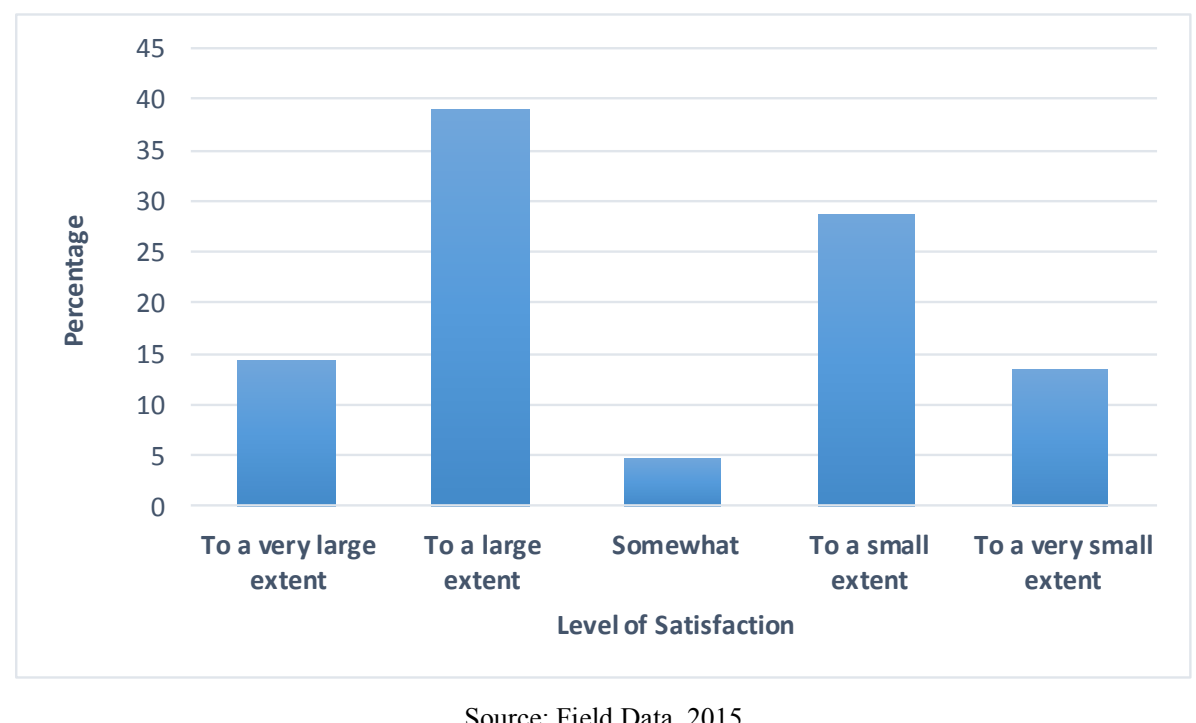

Source: Field Data, 2015

Figure 3. Overall satisfaction level of employees.

The overall satisfaction includes every factor under studied in this research. These factors ranged from physical working conditions, social environment and relationships as well as psychological factors including work content (monotonies of work and fatigue). Quite a number of the respondents (close to $42 \%$ ) are not satisfied with their working conditions in totality. This calls for the need to improve their working conditions as work environment has been found to be positively related to employee job satisfaction [24].

In accessing the general level of working conditions in the bank, $41(39 \%)$ staff were satisfied to a large extent whilst 15 (14\%) out of the 105 respondents were very satisfied to a large extent. $5 \%$ of respondent were indifferent with their level of satisfaction. However, $29 \%$ and $13 \%$ of respondents were to a small extent and to a very small extent respectively satisfied of the working conditions of the bank.

\section{Conclusion}

This paper assessed the level of job satisfaction and staff morale in a merchant bank based on the job environment. It was revealed that, most of the staff of the bank were content with their current work environment. Those who were satisfied ranked that to a large extent of satisfaction and majority of the respondents indicated that they were fairly satisfied. It was also known that, the overall level of job contentment in the bank was fairly satisfactory. A few number of the respondents also affirmed that, confidence on the job in general was not high. With the issue of communality, most staff are affected by the assistance they receive from colleagues and supervisors since this has an impact on job satisfaction and staff morale, it was established that, indeed good relationship and communication has a direct relationship with staff morale and satisfaction at work. The findings from the study emphasize the need for management to improve the work environment of employees to boost productivity.

\section{References}

[1] Smits, S. J. (1972). Counselor Job Satisfaction and employment turnover in state rehabilitation agencies: A follow up study. Journal of Counseling Psychology, 19, 512-517.

[2] Miller, L. A. and Muthard, J. E. (1965). Job Satisfaction and counselor performance in state rehabilitation agencies. Journal of Applied Psychology, 49, 280-283.

[3] Robbins, S. P., Odendaal, A., and Roodt, G. (2003). Organizational Behavior. Global and Southern African Perspectives 9th ed. Cape Town: Pearson Education.

[4] Butler, M. and Rose, N. (2011). Introduction to Organizational Behaviour, Edited. London: Chartered Institute of Personnel \& Development.

[5] Strong, M. H., Jeannerert, P. R., McPhail, S. M., and Bleckley, B. (1999). Work context, taxonomy and measurement of the work environment. American Psychological Association (Houston TX), 86: 12767.

[6] Kaya, E. (1995). Job satisfaction of the librarians in the developing countries. 61st IFLA General conference.

[7] Branham, L. (2005). The 7 hidden reasons employees leave: how to recognize the subtle signs and act before it's too late. New York: Amacom.

[8] Leshabari M, Muhondwa E, Mwangu M, Mbembati N. (2008). Motivation of Health care workers in Tanzania: case study of Muhimbili National Hospital. East African journal of Public Health, 5 (1): 30-36. 
[9] Banbury S. and Berry, D. C. (1998). Disruption of officerelated tasks by speech and office noise. Br. J. Psychol, 89 499-517.

[10] Sundstrom, E. and Sundstrom, M. G. (1986). Work Places: The Psychology of the Physical Environment in Offices and Factories. Cambridge: Cambridge University Press.

[11] Barry, P. Haynes (2008). An Evaluation of the Impact of the Office Environment on Productivity. Journal of Facilities. 26 (5/6), pp. 178-19.

[12] Chandrasekar, K. (2011). Workplace environment and its impact on Organizational performance in Public Sector Organizations: International Journal of Enterprise Computing and Business Systems Vol. 1 Issue 1.

[13] Sarode, A. P. and Shirsath, M. (2014). The factors affecting Employees work environment and its relationship with Employee productivity. International journal of Science and Resource 11 (3): 2735-2737.

[14] Mohamed, G (2005). Competence of maternal and child health clinic workers in detecting malnutrition in Somali, African Health Sciences. (2005), 5 (4): 319-321.

[15] Amible, T. and Kramer, S. (2011), "Do happier people work harder", New York Times, available at: www.nytimes.com/2011/09/04/opinion/sunday/do-happierpeople-work-harder.html

[16] Kreitner, R. and Kinicki, A. (2004). Organizational Behavior. New York: McGraw Hill.
[17] Locke, E. A. (1976). The nature and causes of job satisfaction. In M. D. Dunnette (Ed.), Handbook of industrial and organizational psychology (pp. 1297-1349). Chicago: Rand McNally.

[18] Hoppock, R. (1935). Job Satisfaction. Oxford, England: Harper.

[19] Lu, H., While, A. E. and Barriball, K. L. (2005). Job satisfaction among nurses: a literature review. International Journal of Nursing Studies, 211.

[20] Judge, T. A., Heller, D., and Mount, M. K.. (2002). Five-factor model of personality and job satisfaction: A meta-analysis. Journal of Applied Psychology, 87, 530-54.

[21] Polit, D. F. (2004). Nursing Research: Principles and Methods 7th Edition. Philadelphia: Lippincot Williams and Wilkins.

[22] Salunke, G. (2015). Work Environment and Its Effect on Job Satisfaction in Cooperative Sugar Factories in Maharashtra, India. Abhinav International Monthly Refereed Journal of Research in Management \& Technology, 4 (5), 21-31.

[23] Masum, A. K. M., Azad, M. A. K., \& Beh, L.-S. (2015). Determinants of Academics' Job Satisfaction: Empirical Evidence from Private Universities in Bangladesh. PLoS ONE, 10 (2), e0117834. http://doi.org/10.1371/journal.pone.0117834

[24] Raziq, A. \& Maulabakhsh, R. (2015). Impact of Working Environment on Job Satisfaction. Procedia Economics and Finance, 23, 717-725. 